Thessa Jensen, Associate Professor, Department of Communication and Psychology, Aalborg University, thessa@hum.aau.dk

Henriette Roued-Cunliffe, Associate Professor, Royal School of Library and Information Science, University of Copenhagen, roued@hum.ku.dk

\title{
Researching Internet Content
}

The Web has recently celebrated its 25th anniversary and as Gartner's hype cycle on emerging technology shows this has already given rise to new, emerging technologies, platforms, ways of interacting and creating content.

In the Humanities we traditionally study cultural content in its many different shapes and forms from letters and literature to paintings and pottery. However, many years with the Internet has thoroughly affected the amount, shape, creation of and way we interact with and through the cultural content found on the Internet. This in turn has influenced the theories as well as the methods with which we can study cultural content. In recent years there has been a growing focus on the study of born-digital material, using both newly developed digital methods as well as traditional methods.

In this issue we want to present four very different approaches to using and understanding the Web as it is today.

The first paper, Jessica Austin's “Online Hate and Hurt: Ethical considerations when online research takes an ugly turn", deals with the challenges online researchers might encounter in their data collection when using online platforms like Tumblr. Austin makes a compelling case involving the threats of suicide due to online bullying. As a result of her analysis, Austin provides suggestions for an improvement of ethical research protocols.

In their article, "Det levende web og de døde links" (The living Web and the dead links), Caroline Nyvang, Thomas Hvid Kromann and Eld Zierau show a rather different problematic with the use of Web references in research. Drawing on Danish and international investigations, Nyvang, Kromann and Zierau examine the challenges of reference rot and link rot, making it problematic for readers of scientific papers to ensure easy access to source material and other data. The authors finish their paper with a proposal for a new way of providing links and online references.

Tem Frank Andersen's "Browsing the Origins of Comic Book Superheroes" shows a different side of Web research, focussing on the content and how comic books and participatory platforms give rise to a new way of understanding user participation and content generation.

Finally, Ayoung Yoon, Kyle M. L. Jones and Lydia Spotts examine a new trend in their article "Ethical Use of Lifelogging Data for Research". The tracking and logging of data, in Yoon et al.'s case lifelogging via wearable cameras poses not only new possibilities for the user and for companies, extracting and analysing huge amounts 
of data; it also poses new ethical challenges through the capture and logging of bystanders. The authors end with a discussion of privacy and other ethical issues due to the data gathering methods.

As can be seen from the above, this issue of Nordisk Tidsskrift for Informationsvidenskab og Kulturformidling only just scratches the very surface of Web research. It shows how ethical challenges are prevalent due to ever changing nature of data and data storage, the Web and subsequent technologies are enabling; how new ways of interaction and participation change the culture, both on- and offline; and how research needs to be reinvented and transformed because of the possibilities, new potentials, and capabilities of the Web. 